Original Article

\title{
NEWER OPHTHALMIC IN SITU GEL OF MOXIFLOXACIN HYDROCHLORIDE: OPTIMIZATION USING BOX BEHNKEN STATISTICAL DESIGN
}

\section{MANSI DHOLAKIA, RICHA DAVE, VAISHALI THAKKAR, HARDIK RANA, MUKESH GOHEL, NIRAV PATEL}

Department of Pharmaceutics, Anand Pharmacy College, Anand, 388001, Gujarat, India

Email: dholakiamansi@gmail.com

Received: 22 Jun 2018 Revised and Accepted: 27 Oct 2018

\section{ABSTRACT}

Objective: The present research work aims at describing the formulation and evaluation of the ocular delivery system of moxifloxacin hydrochloride $(\mathrm{MH})$ based on the concept of ion sensitive in situ gelations.

Methods: In situ gel was prepared by a hot method using $0.6 \%$ of gelrite, $0.25 \%$ hydroxypropylmethylcellulose (HPMC $\mathrm{K}_{4} \mathrm{M}$ ) and $0.023 \%$ tamarind gum as bioadhesive polymers for sustained drug release. Optimization was done by Box Behnken Design with different concentration of gelrite ( $\left.\mathrm{X}_{1}\right)$, HPMC $\mathrm{K}_{4} \mathrm{M}\left(\mathrm{X}_{2}\right)$ and tamarind gum $\left(\mathrm{X}_{3}\right)$ as independent variables. In situ gel was optimized based on mucoadhesion index (Y1), Gel strength (Y2) and in vitro drug release (Y3). Influence of the quantitative variable on the dependent variable was predicted by a polynomial equation.

Results: Infrared spectroscopy excluded any interaction between drug and excipients. The selected independent variables significantly influenced the responses and were able to sustain the drug release. The prepared gel with a pH of 6.8 to 7.4 exhibited non-newtonian flow with no ocular irritation. The formulation remained stable with no change in $\mathrm{pH}$ and viscosity after $30 \mathrm{~d}$ of stability study.

Conclusion: Thus, moxifloxacin hydrochloride $(\mathrm{MH})$ in situ gel is a viable alternative to a conventional delivery system with the properties of sustained drug release, prolonged ocular retention, and improved corneal penetration.

Keywords: Moxifloxacin hydrochloride (MH), Box-Behnken Design, Gelrite, HPMC $\mathrm{K}_{4} \mathrm{M}$, Tamarind gum

(C) 2018 The Authors. Published by Innovare Academic Sciences Pvt Ltd. This is an open-access article under the CC BY license (http://creativecommons.org/licenses/by/4.0/) DOI: http://dx.doi.org/10.22159/ijpps.2018v10i12.26979

\section{INTRODUCTION}

Development of suitable drug delivery systems for ocular therapy is one of the major problems being faced by pharmaceutical scientists. Eye, being the most interesting organ due owing to its drug disposition characteristics is considered a convenient route for the topical application of drugs [1]. But the attainment of an optimal concentration at the site of action circumventing the protective barriers of the eye without causing permanent tissue damage offers a significant challenge to the formulator.

Conventional ocular dosage forms result in poor bioavailability due to tear production, nonproductive absorption, transient residence time, and impermeability of corneal epithelium. These physiological and anatomical constraints deliver only a small fraction of the instilled dose of ocular therapeutics and less than $1 \%$ is effectively absorbed and reaches the internal anterior tissue of the eyes [2].

Several methods for prolonging the contact time between drug and corneal-conjunctival epithelium are investigated to increase the drug bioavailability. Various ophthalmic products, such as inserts, ointments, suspensions, and aqueous gels, have been developed to enhance ophthalmic bioavailability. These ocular drug delivery systems, however, have not been used extensively because of some drawbacks, such as blurred vision and poor patient compliance.

As the ocular efficacy of topically applied drugs is influenced by the corneal contact time, in situ gel is the most common method of improving the ocular availability of drugs. In situ gel system is formulated as liquid preparation suitable to be instilled into eyes which upon exposure to the physiologic environment changes to gel, thus prolongs the precorneal residence time and enhances the ocular bioavailability of the drug.

Topical administration of antibacterial medication to the conjunctival sac is usually an effective avenue for treating bacterial conjunctivitis, keratitis, and uveitis but requires frequent instillation. Moxifloxacin, an

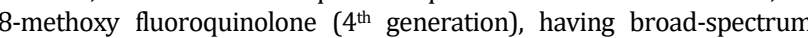

antibiotic activity, with efficacy against various gram-positive and gramnegative microorganisms through inhibition of DNA gyrase and topoisomerases IV and is indicated for severe infections. To increase the bioavailability of moxifloxacin hydrochloride in situ gelling systems can be highly advantageous [3].

In situ gels consist of polymeric networks that can absorb large quantities of water while remaining insoluble in aqueous solutions due to chemical or physical cross-linking of individual polymer chains [4-5]. Increase in solution viscosity by using polymers improves retention of product on the corneal surface. More recently, the newer approach to improve mechanical strength and enhance precorneal resident time of in situ gel is based on the use of mucoadhesive polymers. The principle for the use of bioadhesive polymers relies on their ability to interact with the mucin present on the eye surface. The present investigation uses the ion-sensitive gelling mechanism with $\mathrm{HPMC} \mathrm{K}_{4} \mathrm{M}$ and tamarind gum as potential bioadhesive polymers for the formulation of hydrogels. The formulation also consists of gellan gum as an ion-sensitive polymer which is having good gel strength and biocompatibility [6-8].

In this regard, the present investigation is intended to characterize and evaluate the in situ gel of moxifloxacin hydrochloride, using bioadhesive polymers for sustaining drug release for a longer period. Optimization of the formulation was done using Box-Behnken statistical design (Design Expert ${ }^{\circledR}$ 8.0.7.1). The formulation variables that could affect the release rate and absorption of the drug in topical formulations, such as mucoadhesion strength, gelation strength, and the drug concentration in the formulations, were studied. In addition, the in vivo performance of gel formulation was assessed on the basis of the ocular irritancy in the rabbit's eye [9]

\section{MATERIALS AND METHODS}

Materials

Moxifloxacin hydrochloride $(\mathrm{MH})$ was gifted by MARCK Bioscience Ltd, Kheda. Hydroxy-propylmethylcellulose (HPMC $\mathrm{K}_{4} \mathrm{M}$ ) was 
supplied from colorconasia Pvt. Ltd. Gellan gum (Gelrite) and mucin were supplied from Hi-media Laboratories Pvt. Ltd. Tamarind gum was received from Shivam Exim Ltd, Ahmedabad.

\section{Compatibility study}

The physicochemical compatibility between moxifloxacin hydrochloride $(\mathrm{MH})$ and polymers was studied using Fourier transforms infrared spectroscopy (FTIR) and Differential scanning calorimetric analysis (DSC).

\section{Fourier transform infrared spectroscopy (FTIR)}

The infra-red spectra of pure moxifloxacin hydrochloride (MH) and drug-polymer physical mixture, were recorded using FTIR spectrophotometer (Perkin Elmer-spectrum Bx, USA). Disks of potassium bromide and tested sample mixtures were obtained using hydraulic press before scanning at a range of 4000 through $400 \mathrm{~cm}^{-1}$.

\section{Differential scanning calorimetric (DSC)}

Unprocessed moxifloxacin hydrochloride $(\mathrm{MH})$ and prepared drugpolymer physical mixture were studied regarding their thermal behavior using differential scanning calorimetry (Perkin Elmer DSC7, USA). Aluminum pans loaded with samples equivalent to approximately $2 \mathrm{mg}$ of the drug were crimped. The thermal behavior of each sample was investigated at a heating rate of $10{ }^{\circ} \mathrm{C} / \mathrm{min}$, covering temperature ranges of $25-200{ }^{\circ} \mathrm{C}$. Data analysis was conducted using the TA-60WS thermal analysis software and the transition midpoint ( $\mathrm{Tm}$ ) of the drug was recorded.

\section{Development of ophthalmic in situ gel}

In situ ophthalmic gel was prepared by the hot method as per the composition of each formulation mentioned in table 1 . Gelrite and benzalkonium chloride $(0.0075 \% \mathrm{w} / \mathrm{v})$ were dissolved in $50 \mathrm{ml}$ of sterile water under an agitated condition at $1000 \mathrm{rpm}$ at $90^{\circ} \mathrm{C}$. After complete dissolution, tamarind gum and hydroxypropyl methylcellulose (HPMC $\mathrm{K}_{4} \mathrm{M}$ ) were dissolved in the same condition. The solution was kept at room temperature. Moxifloxacin hydrochloride $(\mathrm{MH})(0.5 \% \mathrm{w} / \mathrm{v})$ and mannitol $(0.5 \mathrm{gm})$ were dissolved separately in water for injection separately at room temperature. The above formulation was then filtered through a polycarbonate filter of $0.45 \mu \mathrm{m}$, and autoclaved at $121^{\circ} \mathrm{C}$ for $20 \mathrm{~min}$ [10-11].

\section{Experimental design}

The Box-Behnken design was used to optimize the formulation parameters and to assess the main effect and interaction effect. The independent and dependent variables are listed in table 1 . Table 2, summarizes an account of the 15 experimental runs studied, their factor combinations, and the translation of the coded levels to the experimental units employed during the study. Mucoadhesion strength, gel strength, and \% drug release were chosen as the response variables. Design expert software (8.0.7.1), trial version, was used for computation. Polynomial models, including interaction and quadratic terms, were generated for all the response variables using multiple linear regression analysis (MLRA) approach. The general form of the model is represented in equation 1. The goal of the experimental design was to find out, with the minimum number of experimental runs, which process variables have the biggest impact on the quality of the final product.

$\mathrm{Yi}=\mathrm{b}_{0}+\mathrm{b}_{1} \mathrm{X}_{1}+\mathrm{b}_{2} \mathrm{X}_{2}+\mathrm{b}_{3} \mathrm{X}_{3}+\mathrm{b}_{12} \mathrm{X}_{1} \mathrm{X}_{2}+\mathrm{b}_{23} \mathrm{X}_{2} \mathrm{X}_{3}+\mathrm{b}_{13} \mathrm{X}_{1} \mathrm{X}_{3}+\mathrm{b}_{11} \mathrm{X}_{1}^{2}+\mathrm{b}_{22} \mathrm{X}_{2}{ }^{2}+\mathrm{b}_{33} \mathrm{X}_{3}{ }^{2}$ (1)

Where, $b_{0}$ is the intercept representing the arithmetic mean response of 15 runs, $b_{1}$ to $b_{33}$ are the regression coefficients, $X_{1}, X_{2}$ and $X_{3}$ are the independent variable. The terms $X_{1}, X_{2}$ and $X_{i 2}(i=1$ to 3) represent the interaction and quadratic term respectively. Box Behnken design was selected due to less number of run for 3 factors and 3 levels.

The constraint for selection of optimum formula were primarily based on the desired values of the response parameters, i.e. gel strength ( $<150$ dyne $/ \mathrm{cm}^{2}$ ), mucoadhesion index (up to 15,000 ) and cumulative percentage drug release up to $12 \mathrm{~h}(>95 \%)$. The formulations corresponding to optimum responses were prepared and evaluated. The resultant experimental data was quantitatively compared with predicted values, and percentage error calculated [12].

Table 1: Variables and constrains in box-behnken experimental design

\begin{tabular}{|c|c|c|c|c|}
\hline \multirow[t]{2}{*}{ Independent variables } & \multicolumn{3}{|c|}{ Levels } & \multirow[t]{2}{*}{ Constrains } \\
\hline & Low & Medium & High & \\
\hline $\mathrm{X}_{1}=$ Concentration of Gelrite $(\% \mathrm{~W} / \mathrm{V})$ & 0.2 & 0.4 & 0.6 & \\
\hline $\mathrm{X}_{2}=$ Concentration of Tamarind gum $(\% \mathrm{~W} / \mathrm{V})$ & 0.0 & 0.05 & 1.0 & \\
\hline $\mathrm{X}_{3}=$ Concentration of $\mathrm{HPMC} \mathrm{K}_{4} \mathrm{M}(\% \mathrm{~W} / \mathrm{V})$ & 0.0 & 0.25 & 0.5 & \\
\hline Transformed values & -1 & 0 & 1 & \\
\hline \multirow[t]{3}{*}{ Dependent variables } & \multicolumn{3}{|c|}{$\mathrm{Y}_{1}=$ Mucoadhesive index (Cps) } & 15,000 \\
\hline & \multicolumn{3}{|c|}{$\mathrm{Y}_{2}=$ Gelation strength $\left(\right.$ dyne $/ \mathrm{cm}^{2}$ ) } & $<150$ dyne $/ \mathrm{cm}^{2}$ \\
\hline & \multicolumn{3}{|c|}{$Y_{3}=$ Drug release up to $12 \mathrm{hr}(\%)$} & $>95 \%$ \\
\hline
\end{tabular}

\section{Data analysis and validation of the model}

The statistical validity of the polynomial equation was established on the basis of ANOVA analysis. Subsequent feasibility and grid search were performed to locate design space for optimum formulations. 3-D and 2-D response surface graphs and contour plots were constructed. Checkpoint batches as per the formula were prepared and evaluated for various responses. Experimental data of all responses were quantitatively compared with that of the predicted values and validity of the model was established.

\section{Evaluation of in situ ophthalmic gel}

\section{Clarity, $\mathrm{pH}$, and viscosity}

Clarity test was performed by visual inspection of each container under a good light, viewed against reflection into the eyes and viewed against a black and white background. The $\mathrm{pH}$ of prepared formulations was measured by a digital $\mathrm{pH}$ meter (Labindia-Pico ${ }^{+}$, Japan). To assess the rheological property of in situ gel, the viscosity of all the prepared batches were measured at 4 shear rate i.e. 50 rpm, $100 \mathrm{rpm}, 150 \mathrm{rpm}$, and $200 \mathrm{rpm}$ using a Brookfield LVDV II
PRO+viscometer. All the measurements were performed in triplicate and mean viscosity was calculated. The rheological flow behavior was determined from the graph of viscosity and shear rate [13].

\section{Drug content}

The drug content was determined for the prepared in situ gel by dissolving an amount equivalent to $50 \mathrm{mg}$ of the drug from each formulation in $50 \mathrm{ml}$ water. After suitable dilution, drug concentration was determined spectrophotometrically at $298 \mathrm{~nm}$. The experiment was performed in triplicate.

\section{Mucoadhesion strength}

In this method mucin dispersion (MUC) $20 \%(\mathrm{w} / \mathrm{w}$ ) was prepared by hydrating dried mucin with phosphate buffer ( $\mathrm{pH} 7.4$ ) for $12 \mathrm{~h}$ at room temperature. Fifteen grams of this dispersion was mixed for 20 min with $5 \mathrm{~g}$ of prepared sol before measurement that yields $15 \%$ $(\mathrm{w} / \mathrm{w})$ of mucin. The viscosity of the prepared sol/mucin system $\left(\eta_{\mathrm{t}}\right)$ and mucin $\left(\eta_{\mathrm{m}}\right)$ were measured at $32{ }^{\circ} \mathrm{C}$ at shear rates of $25,50,100$ and $150 \mathrm{~S}^{-1}$. The viscosity of the prepared sol/phosphate buffer $(\mathrm{pH}$ 7.4) $\left(\eta_{p}\right)$ was determined in the same way [14]. The viscosity 
component due to bioadhesion $\eta_{\mathrm{b}}$ was obtained by the following equation:

$$
\eta_{\mathrm{b}}=\eta_{\mathrm{t}}-\eta_{\mathrm{m}}-\eta_{\mathrm{p}} \ldots
$$

The mucoadhesion index $\mathrm{M}[\mathrm{Pa}]$ was calculated using the shear rate $\mathrm{D}\left[\mathrm{S}^{-1}\right]$ and the viscosity component $\eta_{\mathrm{b}}[\mathrm{mPas}]$ according to the following equation:

$$
M=\eta_{b} * D
$$

\section{Gel strength}

To mimic the in vivo conditions, in situ gel were diluted with simulated tear fluid (40:7) and transferred to a $100 \mathrm{ml}$ cylinder. The gelation was performed at $37^{\circ} \mathrm{C}$. A disc ( $1 \mathrm{~g}$ in weight and $1.5 \mathrm{~cm}$ in diameter) was placed on the surface of the gelled solution in the cylinder, and various weights were placed on gel and gel strength was determined as the minimal weight needed for the gel to travel the disc $5 \mathrm{~cm}$ down. All measurements were performed in triplicate [15].

\section{In vitro diffusion study}

To ensure sustain release behavior of in situ gel, Franz diffusion cell was used. A cellulose acetate membrane (Dialysis membrane with $25 \mathrm{~mm}$ diameter) was adapted to the terminal portion of the cylindrical donor compartment. $3 \mathrm{ml}$ of a formulation containing drug sufficient for establishing sink conditions, was placed into the donor compartment. The receptor compartment contained $15 \mathrm{ml}$ of phosphate buffer solution of $\mathrm{pH} 7.4$, maintained at $37^{\circ} \mathrm{C}$ under mild agitation using a magnetic stirrer. At specific time intervals, aliquots of $1 \mathrm{ml}$ were withdrawn and immediately restored with the same volume of fresh phosphate buffer. The amount of drug released was assessed by measuring the absorbance at $289 \mathrm{~nm}$ using a UV spectrophotometer [16].

\section{Ocular irritation study}

To assess in vivo irritancy study, New Zealand Albino rabbits weighing 3.0-3.5 kg were used. They were treated as prescribed in the "Guide for the Care and Use of Laboratory Animals" (NIH Publication No. 92-93, revised 1985). The preclinical experimental protocol (Protocol no. 1124 dated $8^{\text {th }}$ Oct. 2011) was approved by institutional animal ethics committee as per the guidance of CPCSEA, Ministry of social justice and empowerment, Government of India (Ethical committee Registration number is 277/CPCSEA). Prior to the experiments, the animals were housed in standard cages in a light-controlled room at $19 \pm 1{ }^{\circ} \mathrm{C}$ and $50 \pm 5 \%$ relative humidity, with no restriction of food or water. During the experiments, the rabbits were placed in restraining boxes, where they could move their heads and eyes freely. All experiments were carried out under veterinary supervision. The study was performed according to Modified Draize technique on six male albino rabbits. Rabbits were divided into two groups. Group I served as control group, and Group II was treated with drug formulation. The optimized formulation was instilled daily for a period of $21 \mathrm{~d}$, and the rabbits were observed for redness, swelling, and watering of the eye [17-19].

\section{Stability study}

To assess the formulation stability studies were conducted as per ICH guideline. Optimized formulation was filled in $50 \mathrm{ml}$ of LDPE plastic bottle and kept in the stability chamber at $25 \mathrm{C} \pm 5 \mathrm{C}$ for $3 \mathrm{mo}$. The physical and chemical stability was tested by monitoring change in $\mathrm{pH}$, gelation time, mucoadhesive strength, viscosity, and drug content.

\section{RESULTS AND DISCUSSION}

\section{Drug-polymer compatibility studies}

\section{Fourier transform infrared spectroscopy (FTIR)}

The infrared study was performed to examine any possible interaction between pure drug and additives. Fig. 1 shows the FTIR spectra of moxifloxacin hydrochloride and physical mixture.

Pure moxifloxacin hydrochloride $(\mathrm{MH})$ spectra showed characteristic peaks represented as $\mathrm{C}=0$ stretching vibrations shown at $1709 \mathrm{~cm}^{-1}, \mathrm{~N}-\mathrm{H}$ stretching vibrations at $2949 \mathrm{~cm}^{-1}, \mathrm{O}-\mathrm{H}$ stretching vibration at $3530 \mathrm{~cm}^{-1}$. The FTIR spectrums of physical mixture revealed the main absorption bands of moxifloxacin hydrochloride with no significant changes compared with the spectrum of pure drug. This would suggest the absence of any possible interaction between the drug and polymers.
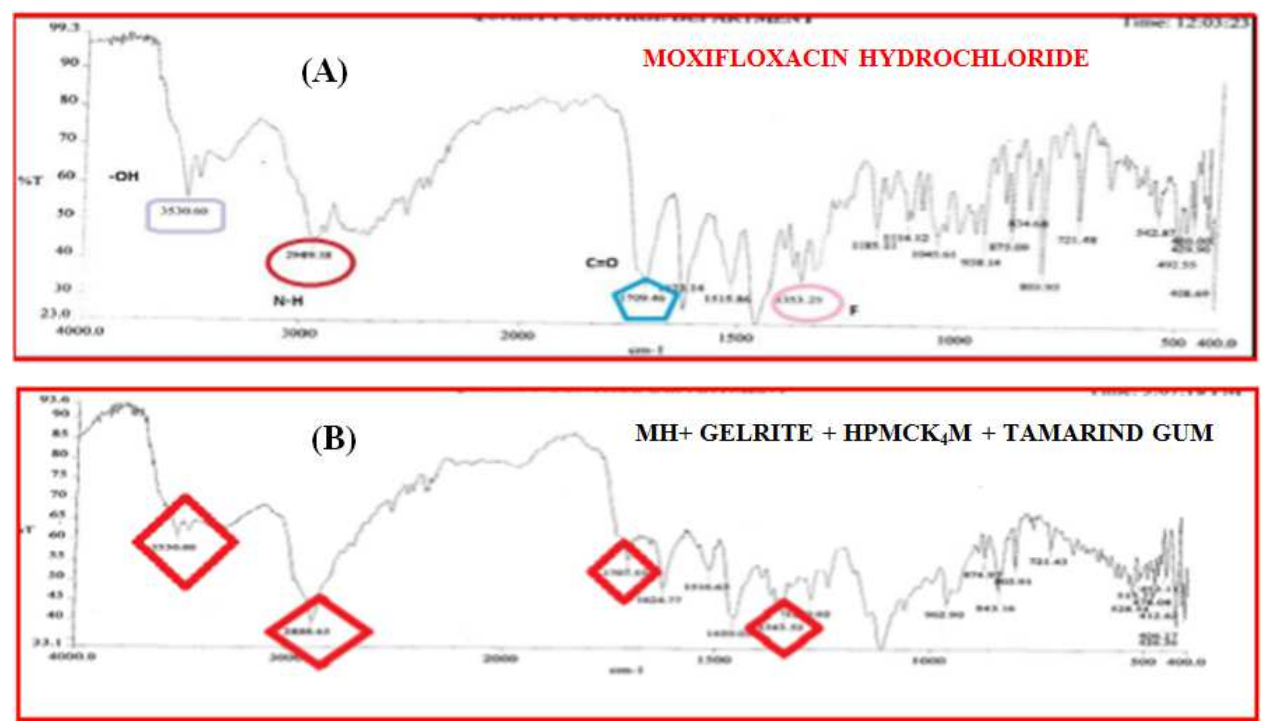

Fig. 1: FTIR spectrum of (A) Moxifloxacin hydrochloride (B) Moxifloxacin hydrochloride-polymer physical mixture

\section{Differential scanning calorimetry (DSC)}

DSC of pure moxifloxacin hydrochloride (MH) and physical mixture are shown in fig. 2. Unprocessed drug exhibited a characteristic sharp endothermic peak at $262.92{ }^{\circ} \mathrm{C}$ corresponding to its melting point. The thermo gram of the investigated physical mixture exhibited the characteristic endothermic peak of $\mathrm{MH}$, indicating the absence of interaction between the two components present in the physical mixture.

\section{Experimental design}

For the response surface methodology involving BBD, a total of 15 experiments were performed for three factors at three levels each. The experiment runs with independent variables and the observed responses for the 15 formulations are shown in table 2 . A suitable polynomial equation involving the individual main effects and interaction factors was selected based on the estimation of several statistical parameters, such as the multiple 
correlation coefficient $\left(\mathrm{r}^{2}\right)$, adjusted multiple correlation coefficient (adjusted $\mathrm{r}^{2}$ ) and the predicted residual sum of squares (PRESS), provided by the Design-Expert software $®$ (8.0.7.1) Trial Version.

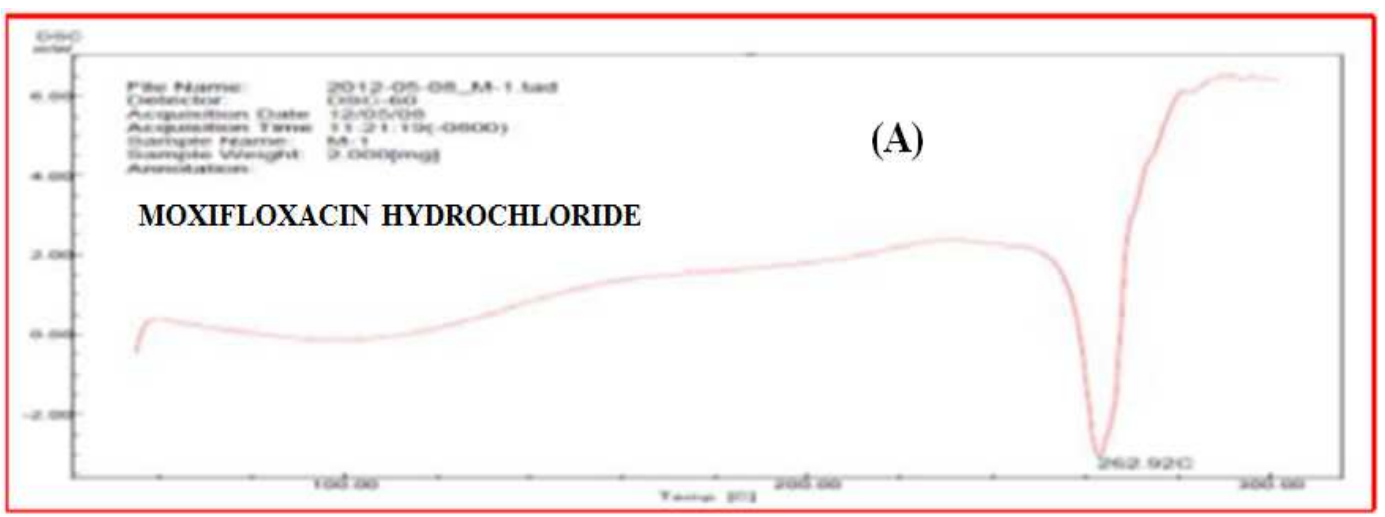

Fig. 2: DSC spectra of (A) Moxifloxacin hydrochloride (B) Moxifloxacin hydrochloride-polymer physical mixture

Table 2: Observed responses in box behnken design for in situ gel

\begin{tabular}{|c|c|c|c|c|c|c|}
\hline \multirow[t]{2}{*}{ Batch no. } & \multicolumn{3}{|l|}{ Coded factor } & \multicolumn{3}{|c|}{ Response } \\
\hline & $\begin{array}{l}\mathrm{X}_{1} \text { (Conc. of Gelrite) } \\
(\%)\end{array}$ & $\begin{array}{l}X_{2} \text { (Conc. of Tamarind Gum) } \\
(\%)\end{array}$ & $\begin{array}{l}\mathrm{X}_{3} \\
\text { (Conc. of HPMC K4M) (\%) }\end{array}$ & $\begin{array}{l}Y_{1} \\
\text { (MI) } \\
\text { Cps }\end{array}$ & $\begin{array}{l}Y_{2} \\
\text { (GS)dyne/cm }\end{array}$ & $\begin{array}{l}Y_{3} \\
\left(C \text { at } \text { at }_{12 h}\right) \% w / w\end{array}$ \\
\hline 1 & 0 & -1 & -1 & 630 & $9.86 \pm 0.02$ & $96.62 \pm 1.21$ \\
\hline 2 & -1 & 0 & 1 & 6675 & $117.73 \pm 2.21$ & $87.54 \pm 0.21$ \\
\hline 3 & -1 & 0 & -1 & 3330 & $25.00 \pm 1.54$ & $98.65 \pm 1.63$ \\
\hline 4 & 0 & -1 & 1 & 1065 & $65.94 \pm 2.32$ & $99.57 \pm 1.90$ \\
\hline 5 & -1 & 1 & 0 & 4545 & $109.18 \pm 1.23$ & $99.28 \pm 2.12$ \\
\hline 6 & 0 & 0 & 0 & 5295 & $145.68 \pm 1.21$ & $95.45 \pm 1.36$ \\
\hline 7 & 0 & 0 & 0 & 5280 & $146.01 \pm 2.21$ & $100.86 \pm 2.24$ \\
\hline 8 & 0 & 1 & -1 & 3870 & $69.2 \pm 1.65$ & $100.13 \pm 1.36$ \\
\hline 9 & 1 & -1 & 0 & 4230 & $117.4 \pm 2.54$ & $98.23 \pm 2.32$ \\
\hline 10 & 1 & 1 & 0 & 9780 & $98.66 \pm 2.36$ & $84.39 \pm 2.64$ \\
\hline 11 & 0 & 0 & 0 & 5865 & $146.34 \pm 2.24$ & $96.01 \pm 3.32$ \\
\hline 12 & 1 & 0 & 1 & 1023 & $156.13 \pm 3.21$ & $87.66 \pm 1.23$ \\
\hline 13 & -1 & -1 & 0 & 1935 & $25.23 \pm 1.21$ & $97.98 \pm 2.82$ \\
\hline 14 & 1 & 0 & -1 & 1860 & $19.8 \pm 2.74$ & $99.91 \pm 2.36$ \\
\hline 15 & 0 & 1 & 1 & 7095 & $97.66 \pm 1.24$ & $87.19 \pm 1.26$ \\
\hline
\end{tabular}

Each value represents the mean $\pm \operatorname{SD}(n=3)$

Data analysis and optimization of formula

\section{Mathematical modeling}

Multiple linear regression analysis (MLRA) and analysis of variance (ANOVA) were carried out employing the Design Expert software 8.0.1.0. to establish a relationship between the three independent variables $\left(\mathrm{X}_{1}\right.$, $\mathrm{X}_{2}$, and $\left.\mathrm{X}_{3}\right)$ and the three dependent variables $\left(\mathrm{Y}_{1}, \mathrm{Y}_{2}\right.$, and $\left.\mathrm{Y}_{3}\right)$ in the Box Behnken design. The results of MLR (the value of the correlation coefficient and the values of coefficients) and ANOVA (Fisher's ratio and $\mathrm{P}$ values) are summarized in table 3 for the three responses.

Table 3: Analysis of variance (ANOVA) for all responses

\begin{tabular}{|c|c|c|c|c|c|c|c|c|c|}
\hline \multirow[t]{2}{*}{ Source } & \multicolumn{3}{|c|}{ Mucoadhesion index $\left(Y_{1}\right)$} & \multicolumn{3}{|l|}{ Gel strength $\left(\mathrm{Y}_{2}\right)$} & \multicolumn{3}{|c|}{ Drug release at12hr $\left(\mathrm{Y}_{3}\right)$} \\
\hline & $\begin{array}{l}\text { Coded } \\
\text { coefficient }\end{array}$ & F Value & p value & Coded coefficient & F value & p value & Coded coefficient & F value & p value \\
\hline Model & 4779.00 & & & 146.01 & & & 95.30 & & \\
\hline $\mathrm{X}_{1}$ & 1201.87 & 4.443 & 0.029 & 14.36 & 2.759 & 0.028 & -1.66 & 1.704 & 0.028 \\
\hline $\mathrm{X}_{2}$ & 2178.75 & 10.781 & 0.220 & 19.53 & 5.108 & 0.157 & -2.68 & 4.443 & 0.068 \\
\hline $\mathrm{X}_{3}$ & 1921.88 & 4.444 & 0.068 & 39.20 & 20.571 & 0.073 & -4.17 & 10.781 & 0.011 \\
\hline $\mathrm{X}_{1} \mathrm{X}_{2}$ & --- & 0.025 & 0.011 & -25.67 & 4.411 & 0.006 & -3.78 & 4.444 & 0.068 \\
\hline $\mathrm{X}_{1} \mathrm{X}_{3}$ & ---- & 4.895 & 0.068 & 10.90 & 0.795 & 0.089 & -0.29 & 0.025 & 0.877 \\
\hline $\mathrm{X}_{2} \mathrm{X}_{3}$ & ---- & 1.09 & 0.877 & -6.91 & 0.319 & 0.413 & -3.97 & 4.895 & 0.040 \\
\hline $\mathrm{X}_{1}^{2}$ & ---- & & ---- & -19.70 & 2.396 & 0.596 & ---- & & ---- \\
\hline $\mathrm{X}_{2}{ }^{2}$ & ---- & & ---- & -38.70 & 9.252 & 0.182 & ---- & & ---- \\
\hline $\mathrm{X}_{3}{ }^{2}$ & ---- & & ---- & -46.65 & 13.445 & 0.028 & ---- & & ----- \\
\hline $\mathrm{X}_{1}^{2} \mathrm{X}_{2}$ & --- & & ---- & & & 0.014 & --- & & --- \\
\hline $\mathrm{r}^{2}$ & 0.973 (Linear) & & & 0.967 (Quadratic) & & & 0.929 (Quadratic) & & \\
\hline
\end{tabular}




\section{Response $Y_{1}$-mucoadhesion index}

The high value of the correlation coefficient (0.973) indicates a good fit between the independent variables and the first dependent variable mucoadhesion index. The linear model was found to be significant as the $\mathrm{P}$ value is less than 0.05 . This result clearly demonstrates that at least any one of the selected independent variables have a statistically significant influence on the mucoadhesion index. Conclusions can be drawn from the numerical values of the coefficients of the main effects and interaction effect. The most significant retardation effect on the mucoadhesion index was shown by the $X_{1}(P=0.029)$ and $X_{1} X_{2}$. This is obvious that gelrite which is a polysaccharide increases the crosslinking and due to that mucoadhesion also increases. Factor $\mathrm{X}_{3}$ should also be considered significant at $P$ value is less than 0.1 . The reason behind this is the polymeric nature of hydroxypropylmethylcellulose ( $\mathrm{HPMC} \mathrm{K}_{4} \mathrm{M}$ ). The contour plot for mucoadhesion index is shown in fig. 3 to facilitate understanding by the reader. The contour lines are linear in nature in the contour plot since only the main terms $\left(\mathrm{X}_{1}\right.$ and $\left.\mathrm{X}_{2}\right)$ were found significant for mucoadhesion index. The equation in terms of un-coded factors is:

\section{$\mathrm{Y}_{1}=4779.00+1201.87 \mathrm{X}_{1}+2178.75 \mathrm{X}_{2}+1921.88 \mathrm{X}_{3}$}

\section{Response $Y_{2}$-gel strength}

High value of the correlation coefficient (0.967) indicates a good fit between the independent variables and gel strength. The quadratic model was found to be significant as the P value is less than 0.05 . This result clearly demonstrates that at least any one of the selected independent variables have a statistically significant influence on the gel strength. Conclusions can be drawn from the numerical values of the coefficients of the main effects, interaction effect, and polynomial terms. The most significant effect on gel strength was shown by, $\mathrm{X}_{1}$ $(P=0.028)$ and $X_{1} X_{2}$ as well as some polynomial terms. From the polynomial equation, it is clear that as the concentration of gelrite increase, the gel strength increases. Factor $X_{3}$ should also be considered significant at $\mathrm{P}$ value is less than 0.1 . The reason behind this is the polymeric nature of hydroxypropylmethylcellulose (HPMC $\mathrm{K}_{4} \mathrm{M}$ ). The contour plot for gel strength is shown in fig. $4 \mathrm{a}, 4 \mathrm{~b}$ and $4 \mathrm{c}$ to facilitate understanding by the reader. The contour lines are curvilinear in nature. The equation in terms of un-coded factors is:

$Y_{2}=146.01+14.36 X_{1}+19.53 X_{2}+39.20 X_{3}-25.67 X_{1} X_{2}+10.90 X_{1} X_{3}-6.91$ $\mathrm{X}_{2} \mathrm{X}_{3}-19.70 \mathrm{X}_{1}^{2}-38.70 \mathrm{X}_{2}^{2}-46.65 \mathrm{X}_{3}^{2}$

\section{Response $\mathrm{Y}_{3}$-drug release at $12 \mathrm{~h}$}

High value of the correlation coefficient $(0.929)$ indicates a good fit between the independent variables and \% cumulative drug released at $12 \mathrm{~h}$. The model is significant with a P value of less than 0.05 . This result clearly demonstrates that at least any one of the selected independent variables have a statistically significant influence on the $\%$ drug released at $12 \mathrm{~h}$. The data are shown in table 3 and fig. $5 \mathrm{a}, 5 \mathrm{~b}$, and $5 \mathrm{c}$ indicate that the concentration of gelrite and concentration of hydroxypropylmethylcellulose (HPMC $\mathrm{K}_{4} \mathrm{M}$ ) have higher drug retardation effect. The equation in terms of un-coded factors is:

$Y_{3}=95.30-1.66 X_{1}-2.68 X_{2}-4.17 X_{3}-3.78 X_{1} X_{2}-0.29 X_{1} X_{3}-3.97 X_{2} X_{3}$
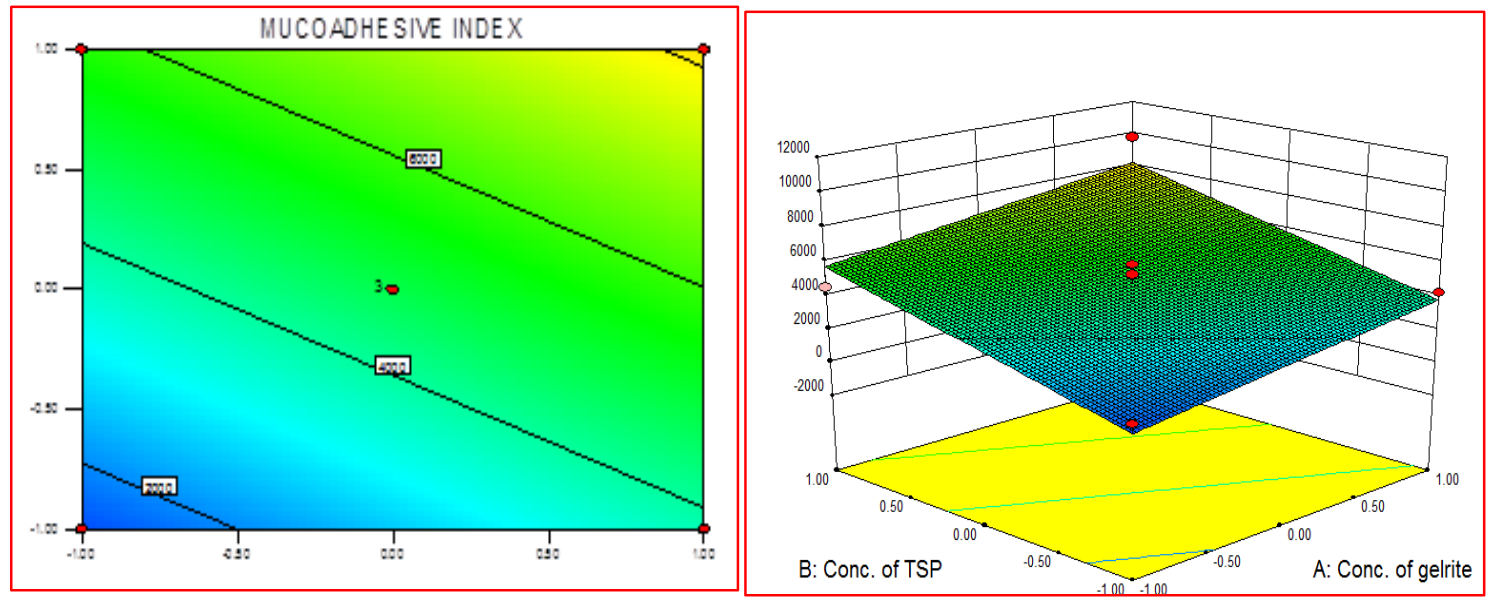

Fig. 3: Contour plot (i) and response surface (ii) plot showing the relationship between various levels of polymer (Conc. of gelrite and Conc. of tamarind Gum) on MI
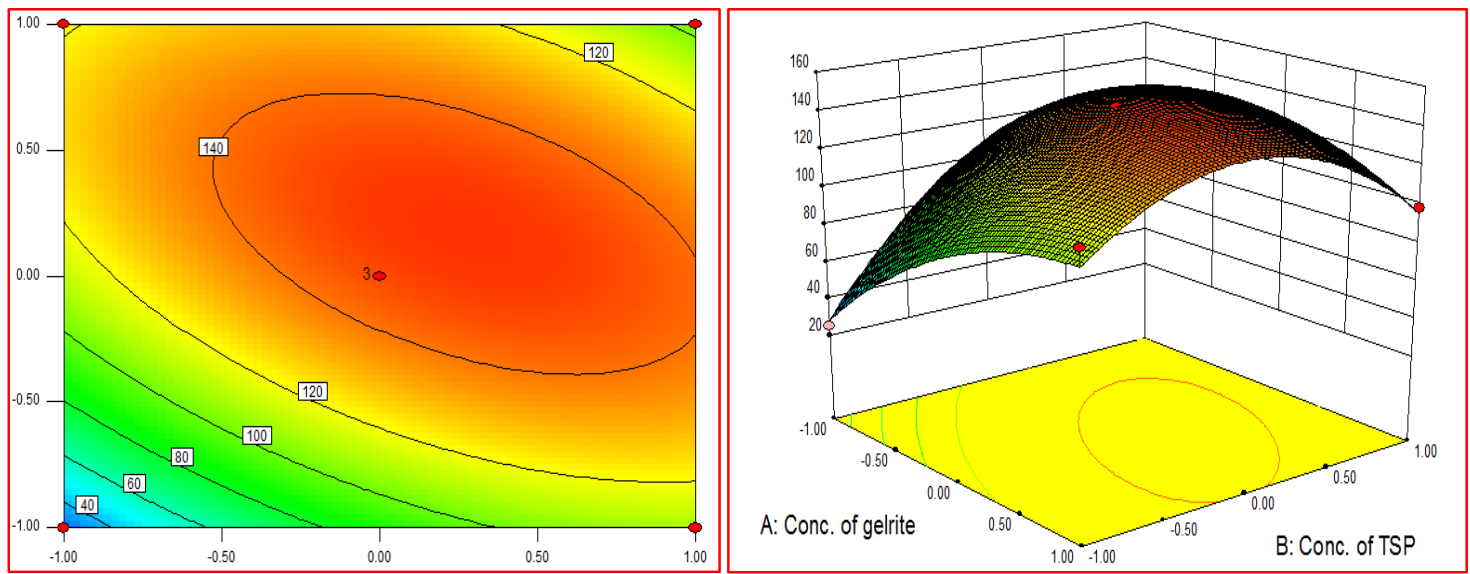

Fig. 4a: Contour plot (i) and response surface (ii) plot showing the relationship between various levels of polymer (Conc. of gelrite and conc. of tamarind gum) on GS 

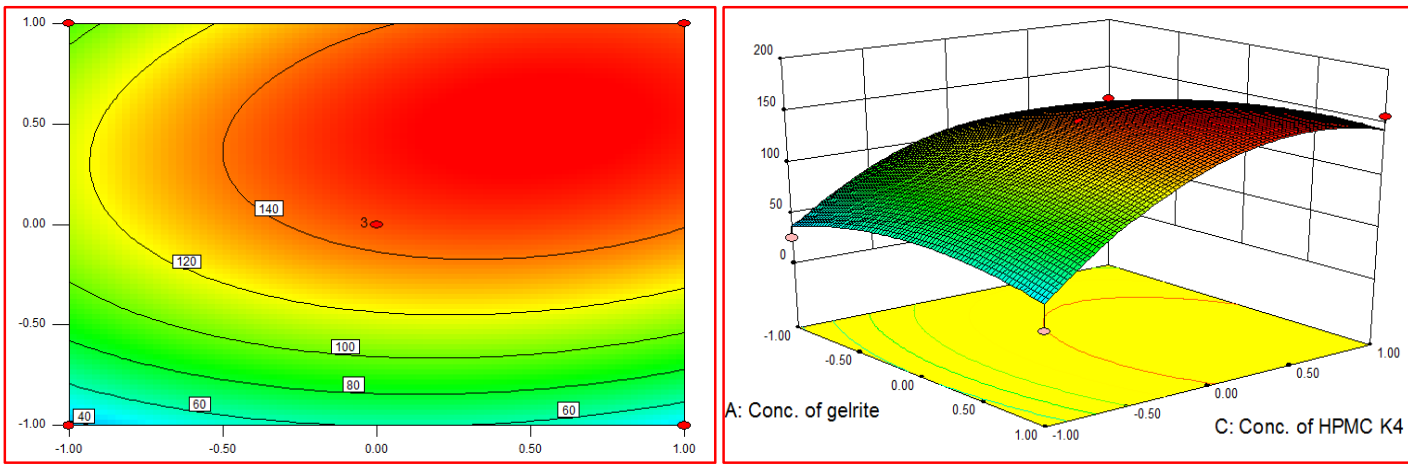

Fig. 4b: Contour plot (i) and response surface (ii) plot showing the relationship between various levels of polymer (Conc. of Gelrite and Conc. of $\mathrm{HPMC} \mathrm{K}_{4} \mathrm{M}$ ) on GS
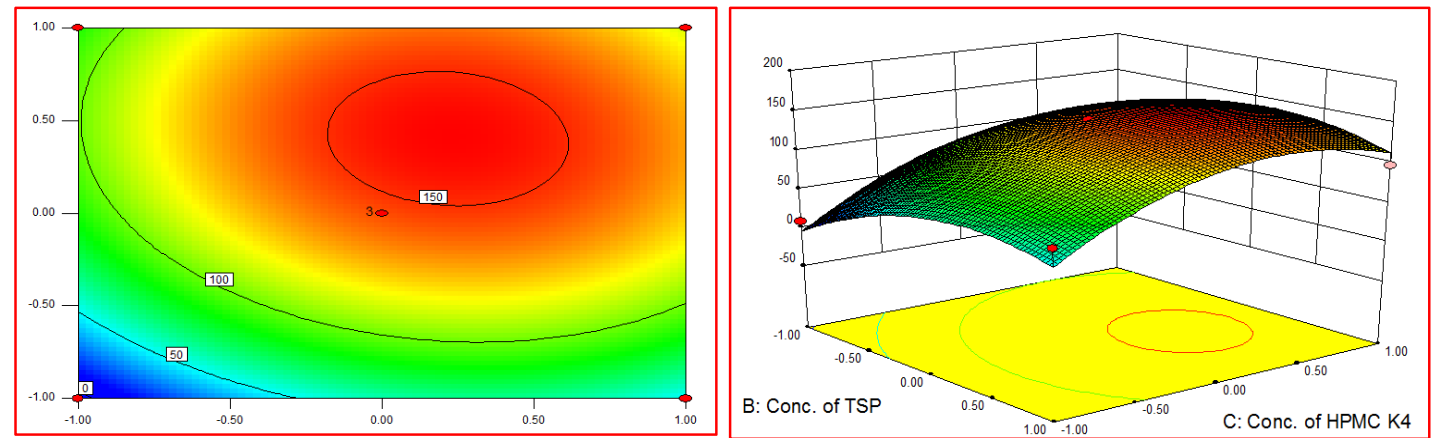

Fig. 4c: Contour plot (i) and response surface (ii) plot showing the relationship between various levels of polymer (Conc. of $\mathrm{HPMC}_{4} \mathrm{M}$ and Conc. of Tamarind Gum) on GS
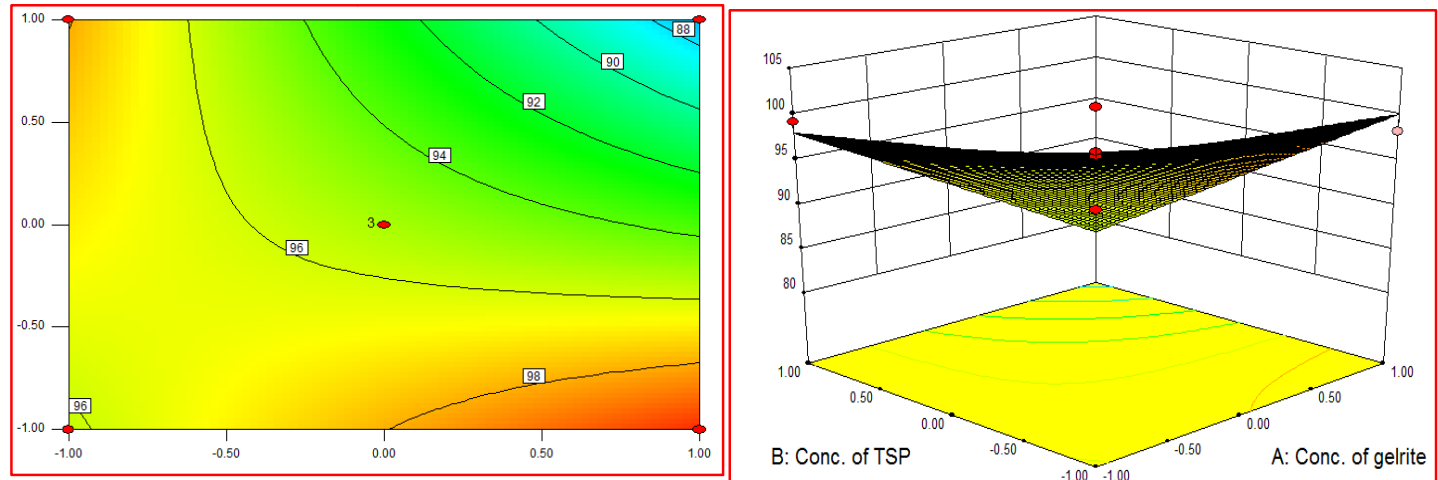

Fig. 5a: Contour plot (i) and response surface (ii) plot showing the relationship between various levels of polymer (Conc. of gelrite and conc. of tamarind gum) on drug release at ${ }_{12 \mathrm{~h}}$
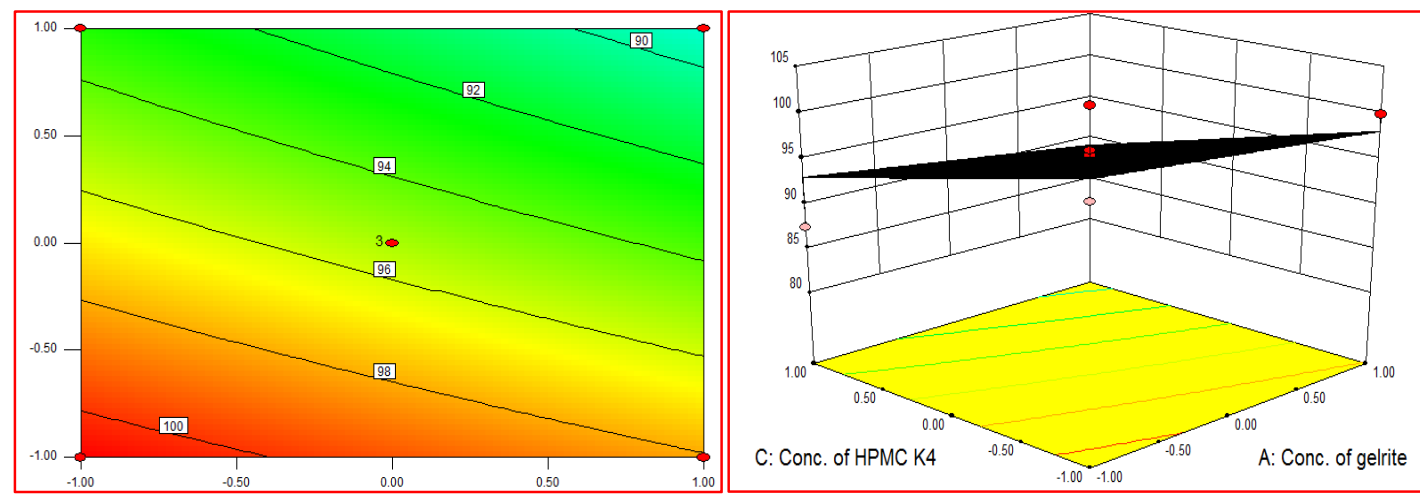

Fig. 5b: Contour plot (i) and response surface (ii) plot showing the relationship between various levels of polymer (Conc. of gelrite and

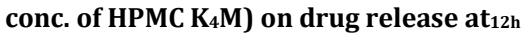



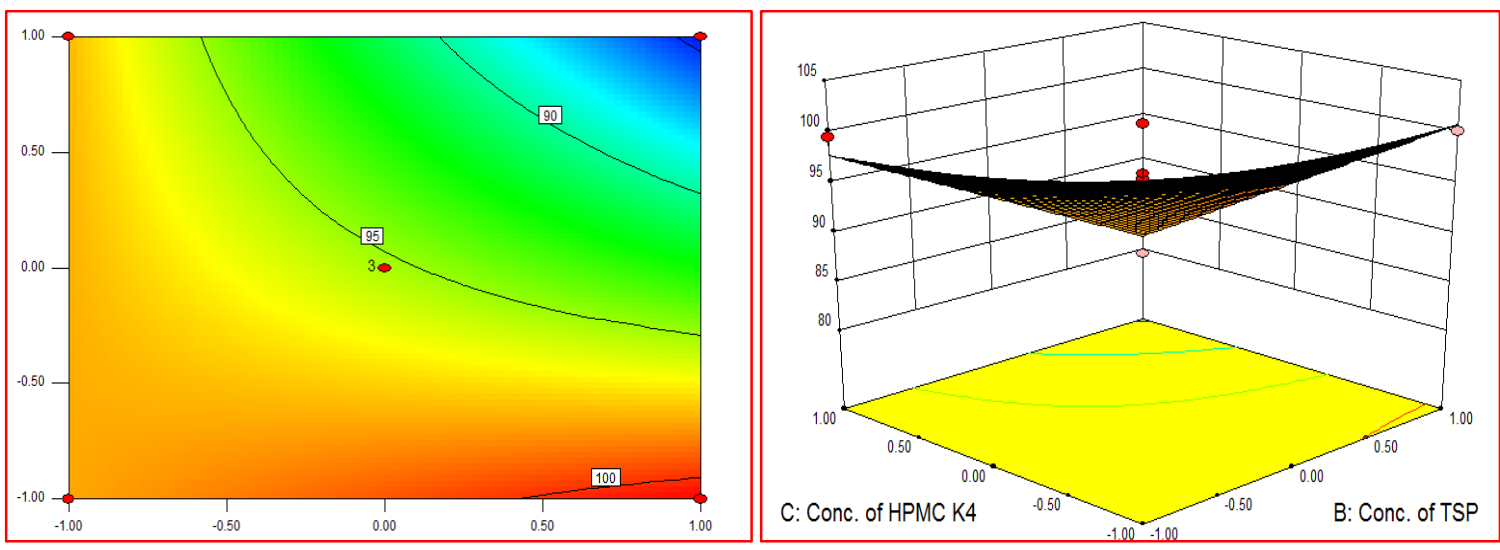

Fig. 5c: Contour plot (i) and response surface (ii) plot showing the relationship between various levels of polymer (Conc. of HPMC $\mathrm{K}_{4} \mathrm{M}$ and conc. of tamarind Gum) on drug release at ${ }_{12 h}$

\section{Design space and validation of response surface methodology}

An ideal product is one which satisfies the requirements of mucoadhesion index, gel strength and drug release at $12 \mathrm{~h}$ to get an idea about the acceptable. It is worthwhile to note that FDA requires that the design space be clearly defined in ANDA. Optimization was achieved by computing overall desirability. The software suggested that when the $0.6 \%$ of gelrite, $0.023 \%$ of tamarind seed polysaccharide and $0.25 \%$ of hydroxypropylmethylcellulose (HPMC $\mathrm{K}_{4} \mathrm{M}$ ) (see the square within the overlaid plot), the three requirements.

To check the reliability of the evolved mathematical models, responses were checked through additional random checkpoint batches covering the entire range of the experimental domain. By the use of grid search analysis, two batches were selected and responses were predicted by the mathematical model. These two additional batches were prepared, and actual responses were recorded. Table 4 shows the composition of check-point formulations, predicted and experimental values of responses and percentage predicted error. Percentage prediction error is helpful in establishing the validity of generated equations and to describe the domain of applicability of the RSM model. The prediction error was found to vary between 1.08 to 3.65. The low magnitudes of error, as well as the significant values of R2 in the present study, prove the high predictive ability of RSM.

Table 4: Composition of checkpoint batch formulation predicted the experimental value of the response variable

\begin{tabular}{|c|c|c|c|}
\hline Check point batches & $\mathbf{M}^{*}$ & $\mathbf{M}^{* *}$ & $\mathbf{M}^{* * *}$ \\
\hline $\mathrm{X}_{1}(\%)$ & 0.6 & 0.6 & 0.6 \\
\hline $\mathrm{X}_{2}(\%)$ & 0.023 & 0.035 & 0.046 \\
\hline $\mathrm{X}_{3}(\%)$ & 0.25 & 0.21 & 0.205 \\
\hline The predicted value of response $\mathrm{Y}_{1}(\mathrm{Cps})$ & 5222.38 & 5441.24 & 5072.02 \\
\hline Actual value of response $\mathrm{Y}_{1}(\mathrm{Cps})$ & 5380 & 5500 & 5172 \\
\hline \% Prediction Error & 3.01 & 1.08 & 1.97 \\
\hline Predicted value of response $Y_{2}\left(\right.$ dyne $\left./ \mathrm{cm}^{2}\right)$ & 137.06 & 141.49 & 136.99 \\
\hline Actual value of response $Y_{2}\left(\right.$ dyne $\left./ \mathrm{cm}^{2}\right)$ & 141 & 145.65 & 142 \\
\hline$\%$ Prediction Error & 2.91 & 2.94 & 3.65 \\
\hline Predicted value of response $\mathrm{Y}_{3}(\% \mathrm{w} / \mathrm{w})$ & 98.15 & 97.37 & 98.09 \\
\hline Actual value of response $\mathrm{Y}_{3}(\% \mathrm{w} / \mathrm{w})$ & 99.46 & 99.36 & 96.02 \\
\hline \% Prediction Error & 1.31 & 2.04 & 2.11 \\
\hline
\end{tabular}

\#predicted error $(\%)=$ (observed value-predicted value) $/$ predicted value×100 \%., $\mathrm{M}^{*}$ Optimized Batch, $\mathrm{M}^{*}$ and $\mathrm{M}^{* *}$ Check point batches having desirability near 0.99 from grid search

\section{Evaluation of in situ gel}

\section{Clarity, pH, viscosity}

Clarity of all formulations was found satisfactory. The formulations were light yellow in color. Terminal sterilization with autoclaving had no effect on physicochemical properties of the formulation. The $\mathrm{pH}$ was within the acceptable range (6.8 to 7.4). The successful use of in situ gels for ocular delivery is not only dependent on properties after administration but is also important that they are easy to administer, by dropping, into the eye. It should exhibit low viscosity for reproducible dose administration. Gelrite containing formulations were mixed with STF in 1:1 dilution showed the drastic difference in viscosity confirming phase transitions from sol to gel as gelrite is a cationic sensitive polymer. In this condition, formulations possessed Non-Newtonian flow, i.e., by increasing shear stress, shear thinning of the formulation was observed. This increasing shear rate mimics ocular shear rates associated with normal blinking which is extremely wide, ranging from $0.03-28500 \mathrm{~S}-1$. Viscosities of prepared formulations were found in a range of 10 to $150 \mathrm{cps}$ and exhibited Non-Newtonian flow [20-21].

\section{Drug content}

Drug content of the prepared in situ gel was in the range of $98-99 \%$ $\mathrm{w} / \mathrm{w}$, excluding any possibility for segregation of drug or additives during preparation.

\section{Mucoadhesive index (MI)}

The mucoadhesive index is an important physicochemical parameter for in situ forming ophthalmic gels since it prevents the formulation from rapid drainage and hence lengthens its precorneal residence time. It shows adhesive forces between polymer molecule and mucous membrane. Results of the determination of mucoadhesive forces of all the prepared formulations are tabulated in table 2 [22].

\section{Gelation strength (GS)}

Gel strength shows cohesive forces between polymer molecules. All formulations exhibited good gel strength. Results of gel strength are presented in table 2 [23]. 


\section{Ocular irritation test}

The optimized batch $\mathrm{M}^{*}$ was selected for the ocular irritation test. The formulation for instilled daily for $21 \mathrm{~d}$ and was found to be nonirritating with no ocular damage to the cornea, iris or conjunctivae and moreover, redness and swelling was also not observed in the experimental animals (fig. 6).

Thus, batch $\mathrm{M}^{*}$ was considered as therapeutically safe, efficacious and suitable for the ocular delivery of the drug [9].

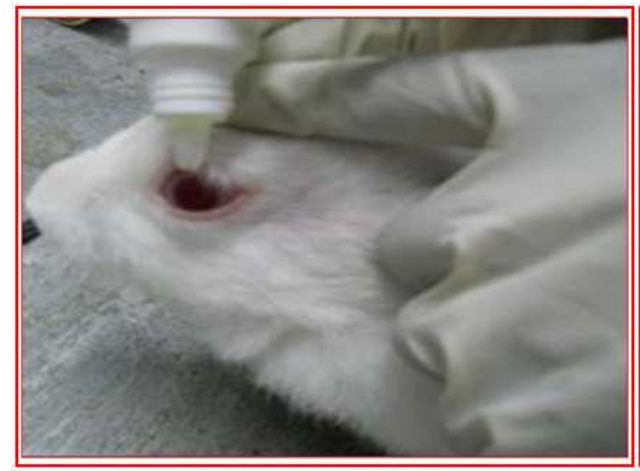

A

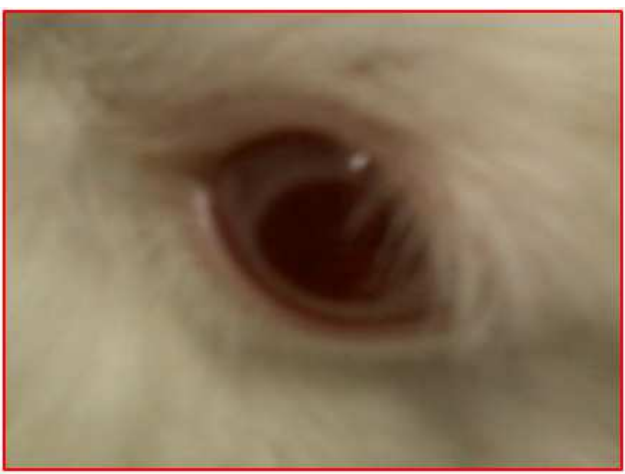

B

Fig. 6: Ocular irritation test (A) rabbit eye before ocular irritation test (B) Rabbit eye after ocular irritation test

\section{Stability studies}

Stability study of optimized formulation was performed as per ICH guideline. The sample was evaluated for in vivo release study, gel strength, mucoadhesive strength, and viscosity. Variation in value was found within $\pm 3 \%$ of initial value. This study shows that no change or degradation was found in moxifloxacin hydrochloride in situ gel (table 5).

Table 5: Stability study data of optimized formulation

\begin{tabular}{llll}
\hline Parameter & $\mathbf{5 ~ d}$ & After 15 d & After 30 d \\
\hline Appearance & Acceptable & Acceptable & Acceptable \\
Viscosity & $48.01 \pm 0.15$ & $48.22 \pm 0.14$ & $49.32 \pm 0.32$ \\
pH & $7.06 \pm 0.11$ & $7.10 \pm 0.10$ & $7.26 \pm 0.11$ \\
\hline
\end{tabular}

Each value represents the mean \pm SD $(n=3)$

\section{CONCLUSION}

In this study, moxifloxacin hydrochloride (MH) in situ gel was successfully prepared using gelrite, hydroxypropylmethylcellulose (HPMC $\left.\mathrm{K}_{4} \mathrm{M}\right)$ and tamarind gum. However, preclinical and clinical studies are necessary for commercialization of dosage form. In situ ophthalmic gel was optimized using Box Behnken design. The influence of quantitative factors was predicted by a polynomial equation. Based on optimization, it was concluded that batch containing $0.6 \%$ gelrite, 0.023 $\%$ tamarind gum and $0.25 \%$ hydroxypropylmethylcellulose (HPMC $\mathrm{K}_{4} \mathrm{M}$ ) gave maximum residence time and better efficacy. On the basis of in vivo ocular irritancy study, it was found that optimized formulation was nonirritant. Thus, this dosage form might be a promising delivery system of ophthalmic drugs with increased bioavailability.

\section{AUTHORS CONTRIBUTIONS}

All the author have contributed equally

\section{CONFLICT OF INTERESTS}

Declared none

\section{REFERENCES}

1. Ludwig A, van Haeringen NJ, Bodelier VM, Van Ooteghem M. Relationship between precorneal retention of viscous eye drops and tear fluid composition. Int Ophthalmol 1992; 16:23-6.

2. Liu L, Tiffany J, Dang Z, Dart JKG, Watson SL, Daniels JT. Nourish and nurture: development of an ocular nutrient lubricant. Investig Ophthalmol Vis Sci 2009;50:2932-9.

3. Release C, Situ IN, Moxifloxacin F, Drug O. Controlled Release in Situ Forming Moxifloxacin; 2010.
4. Katiyar S, Pandit J, Mondal RS, Mishra AK, Chuttani K, Aqil M. In situ gelling dorzolamide loaded chitosan nanoparticles for the treatment of glaucoma. Carbohydr Polym 2014;102:117-24.

5. Tayel SA, El-Nabarawi MA, Tadros MI, Abd-Elsalam WH. Promising ion-sensitive in situ ocular nanoemulsion gels of terbinafine hydrochloride: design, in vitro characterization and in vivo estimation of the ocular irritation and drug pharmacokinetics in the aqueous humor of rabbits. Int J Pharm 2013;443:293-305.

6. Maheswaran A, Padmavathy J, Nandhini V, Saravanan D, Angel P. Formulation and evaluation of floating oral in situ gel of diltiazem hydrochloride. Int J Appl Pharm 2017;9:1-4.

7. Kassab HJ, Thomas LM, Jabir SA. Development and physical characterization of a periodontal bioadhesive gel of gatifloxacin. Int J Appl Pharm 2017;9:10-5.

8. Ahmed VA, Goli D. Development and characterization of in situ gel of xanthan gum for the ophthalmic formulation containing brimonidine tartrate. Asian J Pharm Clin Res 2018;11:277-84.

9. Rathore KS. Development and in vivo in vitro characterizations of timolol maleate in-situ gels. Int J Pharma Bio Sci 2011;2:248-63.

10. Liu Z, Li J, Nie S, Liu H, Ding P, Pan W. Study of an alginate/HPMC-based in situ gelling ophthalmic delivery system for gatifloxacin. Int J Pharm 2006;315:12-7.

11. Gupta SK, Singhvi IJ. Sustained ophthalmic delivery of moxifloxacin hydrochloride from an pH-triggered in situ gelling system. Res J Pharm Technol 2012;5:1538-42.

12. Ibrahim HM, Ahmed TA, Hussain MD, Rahman Z, Samy AM, Kaseem AA. Development of meloxicam in situ implant formulation by quality by design principle. Drug Dev Ind Pharm 2014;40:66-73. 
13. Sulaiman HT, Kassab HJ. Preparation and characterization of econazole nitrate inclusion complex for ocular delivery system. Int J App Pharm 2018;10:175-81.

14. Srivastava R, Srivastava S, Singh SP. Thermoreversible in-situ nasal gel formulations and their pharmaceutical evaluation for the treatment of allergic rhinitis containing extracts of moringa olifera and embelia ribes. Int J App Pharm 2017;9:16-20.

15. El-Kamel A, El-Khatib M. Thermally reversible in situ gelling carbamazepine liquid suppository. Drug Delivery J Delivery Target Ther Agents 2006;13:143-8.

16. He W, Guo X, Feng M, Mao N. In vitro and in vivo studies on ocular vitamin a palmitate cationic liposomal in situ gels. Int J Pharm 2013;458:305-14.

17. Di Colo G, Zambito Y, Zaino C, Sans M. Selected polysaccharides at the comparison for their mucoadhesiveness and effect on the precorneal residence of different drugs in the rabbit model. Drug Dev Ind Pharm 2009;35:941-9.

18. Gan L, Gan Y, Zhu C, Zhang X, Zhu J. Novel microemulsion in situ electrolyte-triggered gelling system for ophthalmic delivery of lipophilic cyclosporine a: in vitro and in vivo results. Int J Pharm 2009;365:143-9.

19. Rozier A, Mazuel C, Grove J, Plazonnet B. Gelrite®: a novel, ion-activated, in-situ gelling polymer for ophthalmic vehicles. Effect on the bioavailability of timolol. Int J Pharm 1989;57:163-8.

20. Uccello-Barretta G, Nazzi S, Zambito Y, Di Colo G, Balzano F, Sansò M. Synergistic interaction between TS-polysaccharide and hyaluronic acid: implications in the formulation of eye drops. Int J Pharm 2010;395:122-31.

21. Bhowmik M, Das S, Chattopadhyay D, Ghosh LK. Study of thermo-sensitive in-situ gels for ocular delivery. Sci Pharm 2011;79:351-8.

22. Srinivasan B, Ganta A, Rajamanickam D, Veerabhadraiah BB, Varadharajan M. Evaluation of tamarind seed polysaccharide as a drug release retardant. Int J Pharm Sci Rev Res 2011;9:27-31.

23. Mohan EC, Kandukuri JM, Allenki V. Preparation and evaluation of in-situ-gels for ocular drug delivery. J Pharm Res 2009;2:1089-94. 